\title{
PERUMUSAN PROGRAM KOMUNIKASI PEMASARAN TERPADU GREEN TEA CHOCOBAR ARAFA TEA DENGAN PENDEKATAN BENCHMARKING
}

\author{
${ }^{1}$ Alan Arif Dharmasaputra, ${ }^{2}$ Yati Rohayati, ${ }^{3}$ Atya Nur Aisha \\ 1,2,3 Program Studi Teknik Industri, Fakultas Rekayasa Industri, Telkom University \\ 1alan.arif.d@gmail.com, ${ }^{2}$ yati.rohayati.ittelkom@gmail.com, ${ }^{3}$ atyanuraisha@gmail.com
}

\begin{abstract}
Abstrak- Arafa Tea adalah Usaha Kecil Menengah (UKM) memproduksi produk olahan teh hijau. Salah satu produk unggulannya yaitu Green Tea (GTC), yang berkontribusi besar terhadap pendapatan Arafa Tea. Namun karena daerah pemasaran masih sempit yaitu Ciburial dan Lembang dan cara komunikasi pemasaran yang digunakan hanya menggunakan kegiatan pameran, Arafa Tea memiliki keinginan untuk memperluas pasar untuk konsumen yang tinggal di Kota Bandung. Penelitian ini bertujuan untuk merumuskan program komunikasi pemasaran yang dapat diterapkan oleh Arafa Tea dalam memasarkan produk GTC. Penelitian ini dilakukan dengan menggunakan metode benchmarking terhadap bisnis serupa dan pesaing langsung untuk menemukan best practice sebagai dasar untuk merumuskan program komunikasi pemasaran untuk Arafa Tea. Parameter yang dijadikan acuan adalah media dan konten komunikasi yang digunakan, pemasaran stretegi, program komunikasi pemasaran. Program yang direkomendasikan akan disesuaikan dengan kemampuan dan sumber daya yang dimiliki UKM Arafa Tea. Berdasarkan hasil analisis benchmarking yang telah dilakukan Arafa Tea memiliki potensi untuk memasarkan produk mereka ke kota Bandung. Untuk itu Arafa Teh perlu mengimplementasi program komunikasi pemasaran terpadu yang telah dirumuskan yaitu kemasan yang dirancang oleh desainer, penggunaan media internet, yaitu Facebook sebagai media komunikasi dan program reseller.
\end{abstract}

Kata kunci: Program Komunikasi Pemasaran Terpadu, Analisis Benchmarking

\section{PENDAHULUAN}

UKM merupakan salah satu kontributor terbesar terhadap GDP Indonesia, yaitu sebanyak 57\% dari total GDP [1]. Salah satu UKM tersebut adalah Arafa Tea yang fokus pada produk olahan teh hijau yang berlokasi di Jalan Dago Pakar Timur, Desa Ciburial. Arafa Tea memiliki beberapa produk yaitu opak green tea, green tea latte, masker green tea, bubuk teh hijau, green tea chocolate (GTC) dan teh instan. Namun untuk tahun-tahun berikutnya Arafa Tea akan fokus pada penjualan produk GTC, karena memberikan kontribusi terbesar terhadap total pendapatan
Arafa Tea. Gambar 1 menunjukkan penjualan Arafa Tea selama 4 tahun.

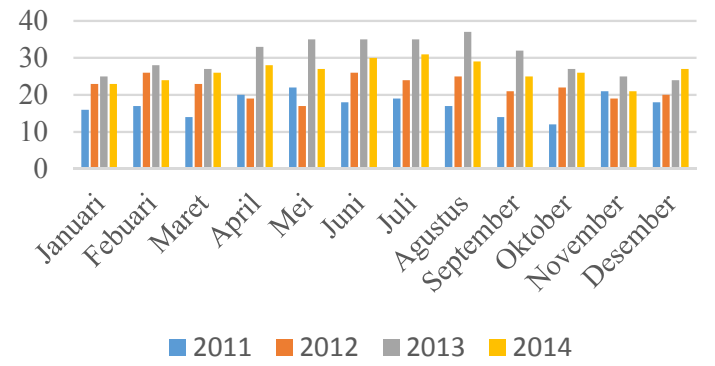

Gambar 1 Total penjualan Arafa Tea

Berdasarkan Gambar 1 dapat dilihat bahwa penjualan Arafa Tea tidak stabil dan tidak menunjukkan tanda-tanda peningkatan. Hal ini membuat Arafa ingin menstabilkan penjualan dengan memperluas pasar ke Kota Bandung dan menargetkan produk untuk anak muda. Hal ini karena anak muda dapat membuat dan mengikuti tren dengan cepat. Oleh karena itu survei pendahuluan dilakukan untuk mendapatkan respon dari anak muda dengan rentang umur 18 hingga 30 tahun yang berdomisili di Kota Bandung untuk produk GTC Arafa Tea, pemilihan respondenden disesuaikan dengan target perluasan pasar Arafa Tea.

BENCHMARKING ANTARA ARAFA TEA DENGAN TAMA COKELAT

\begin{tabular}{|l|l|l|}
\hline & Respon & Keterangan \\
\hline Rasa & $\begin{array}{l}57 \% \text { Menyukai produk } \\
\text { GTC Arafa Tea. }\end{array}$ & $\begin{array}{l}\text { Rasa cokelat dan green } \\
\text { tea telah seimbang }\end{array}$ \\
\hline Promosi & $\begin{array}{l}14 \% \text { Mengetahui } \\
\text { produk GTC Arafa Tea. }\end{array}$ & $\begin{array}{l}\text { Arafa Tea kurang } \\
\text { melakukan promosi. }\end{array}$ \\
\hline
\end{tabular}

Berdasarkan Tabel 1. dapat dilihat sebanyak 57\% responden menyukai produk GTC dan hanya $14 \%$ yang mengetahui tentang GTC Arafa Tea. Dapat disimpulkan bahwa GTC Arafa telah diterima di pasar tetapi proses komunikasi pemasaran yang dilakukan untuk mempromosikan produk GTC masih belum 
efektif. Berdasarkan hal tersebut penelitian ini akan fokus pada perumusan program komunikasi pemasaran GTC Arafa Tea, hal ini dikarenakan komunikasi pemasaran dapat meningkatkan brand equity, brand identity dan penjualan produk [2].

\section{TINJAUAN PUSTAKA}

\section{A. Benchmarking}

Benchmarking adalah proses perbandingan antara suatu organisasi, rencana atau proses dengan pesaing untuk mengetahui apakah kinerja yang telah dilakukan sudah baik atau tidak bila dibandingkan dengan pesaing yang melakukan kegiatan yang sama [3]. Definisi lain dari benchmarking adalah pendekatan yang terdapat pengukuran, perbandingan, identifikasi kegiatan terbaik, implementasi dan perbaikan [4]. Ada 4 jenis benchmarking [5], yaitu:

1. Internal, dilakukan untuk membandingkan unit dalam organisasi.

2. Competitive, dilakukan terhadap kompetitor langsung.

3. Functional, dilakukan terhadap industri dalam pasar yang sama yang memiliki best practice.

4. Generic, dilakukan pada organisasi yang sangat berbeda dengan subyek benchmarking.

\section{B. Komunikasi pemasaran}

Komunikasi pemasaran adalah istilah dalam komunikasi produk atau jasa dengan menggunakan media komunikasi. Tapi sekarang istilah tersebut telah diganti dengan Integrated Marketing Communication (IMC). Hal ini disebabkan karena praktek komunikasi pemasaran tidak hanya fokus pada penggunaan satu media komunikasi, tetapi penggunaan beberapa media yang berbeda namun saling mendukung satu sama lain dan memiliki tujuan yang sama [6]. Ada 4 kategori komunikasi pemasaran seperti:

1. Mass communication

2. In-store communication

3. Targeted communication

4. Personal communication

Dalam komunikasi pemasaran, iklan selalu menjadi fokus utama dalam pelaksanaan komunikasi dengan konsumen dan juga sebagai elemen utama dalam program komunikasi pemasaran. Tapi iklan tidak merupakansatusatunya unsur dalam membangun ekuitas merek dan meningkatkan penjualan[7]. Unsur lain dalam komunikasi pemasaran adalah:
1. Advertising
4. Sales promotion
2. Direct marketing
3. Interactive marketing
5. Publicity
6. Personal selling

\section{Performance measurement}

Performance measurement merupakan alat dalam benchmarking yang digunakan untuk mengukur prosesproses yang ada dalam suatu kegiatan. Dalam pemasaran, pengukuran kinerja digunakan untuk menentukan efisiensi dan efektivitas proses pemasaran dengan pesaing.
Keuntungan dari data pengukuran kinerja dapat diperoleh dan dipahami dengan mudah [8].

\section{METODOLOGI PENELITIAN}

Model konseptual yang digunakan untuk mengGambarkan variabel yang akan digunakan dan dicari dalam penelitian ini untuk merumuskan program komunikasi pemasaran. Gambar 2 menunjukkan model konseptual yang digunakan pada penelitian ini.

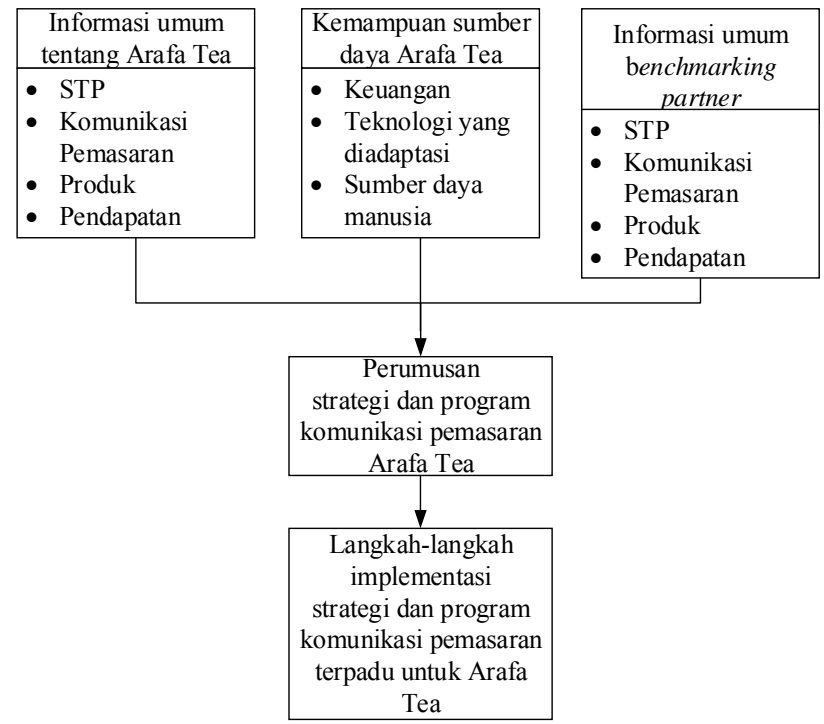

Gambar 2 Model konseptual

Dalam model konseptual dapat dilihat bahwa langkah pertama yang harus dilakukan adalah mengidentifikasi beberapa faktor pemasaran (STP, komunikasi pemasaran, produk dan pendapatan) dari Arafa Tea dan obyek benchmarking yaitu Chocodot dan Maicih. Hal ini bertujuan untuk mengidentifikasi kesamaan yang dimiliki dan juga sebagai dasar untuk perumusan program komunikasi pemasaran. Pada variabel model konseptual juga ditemukan dalam bentuk kemampuan dan sumber daya setelah proses benchmarking Arafa Tea dengan program komunikasi pemasaran yang menghasilkan tujuan yang dapat diimplementasikan oleh Arafa Tea.

\section{PENGUMPULAN DAN PENGOLAHAN DATA}

Pada tahap ini akan dijelaskan tentang pengumpulan dan pengolahan data dalam penelitian ini untuk mendapatkan informasi yang akan berfungsi sebagai rekomendasi untuk Arafa Tea. Data yang diperlukan dalam penelitian ini berasal dari hasil wawancara dengan pemilik bisnis atau pihak yang mengetahui tentang proses bisnis. Pengumpulan data dalam penelitian ini terdiri dari beberapa tahap: 
A. Identifikasi Komunikasi Pemasaran Saat Ini

Identifikasi dilakukan dengan menggunakan bauran komunikasi pemasaran. Hal ini dimaksudkan untuk mempermudah indentifikasi.

TABEL II

IDENTIFIKASI IMC

\begin{tabular}{|l|c|c|c|}
\hline \multicolumn{1}{|c|}{$\begin{array}{c}\text { Bauran } \\
\text { komunikasi } \\
\text { pemasaran }\end{array}$} & $\begin{array}{c}\text { Penerapan } \\
\text { pada Arafa } \\
\text { Tea }\end{array}$ & $\begin{array}{c}\text { Penerapan } \\
\text { pada } \\
\text { Chocodot }\end{array}$ & $\begin{array}{c}\text { Penenrapan } \\
\text { pada } \\
\text { Maicih }\end{array}$ \\
\hline Advertising & $\sqrt{ }$ & \multicolumn{2}{|c|}{$\sqrt{ }$} \\
\hline $\begin{array}{l}\text { Sales } \\
\text { Promotion }\end{array}$ & $\sqrt{ }$ & $\sqrt{ }$ \\
\hline $\begin{array}{l}\text { Public Relation } \\
\text { \& Publicity }\end{array}$ & $\sqrt{ }$ & $\sqrt{ }$ & $\sqrt{ }$ \\
\hline $\begin{array}{l}\text { Direct } \\
\text { Interactive } \\
\text { Marketing }\end{array}$ & $\sqrt{ }$ & $\sqrt{ }$ & $\sqrt{ }$ \\
\hline $\begin{array}{l}\text { Personal } \\
\text { Selling }\end{array}$ & $\sqrt{ }$ & $\sqrt{ }$ & $\sqrt{ }$ \\
\hline $\begin{array}{l}\text { Event } \\
\text { Experience }\end{array}$ & $\sqrt{ }$ & $\mathrm{x}$ & $\sqrt{ }$ \\
\hline $\begin{array}{l}\text { Word of Mouth } \\
\text { Marketing }\end{array}$ & $\sqrt{ }$ & & \\
\hline
\end{tabular}

Berdasarkan hasil analisis perbedaan dalam program komunikasi pemasaran yang dilakukan pada Tabel 2 diperoleh informasi bahwa perbedaan yang paling signifikan ditemukan dalam kategori sales promotion dan event and experience. Sales promotion hanya dilakukan oleh Arafa Tea, dapat dilihat dari pemberian sampel produk yang dilakukan di setiap acara pameran yang diikuti oleh Arafa Tea. Sementara Chocodot dan Maicih tidak melakukan promosi penjualan dengan pertimbangan efisiensi biaya. Chocodot dan Maicih memilih untuk melakukan sponsorship acara dengan kegiatan sesuai dengan target pasar.

B. Identifikasi Kemampuan dan Sumber Daya Arafa Tea

Sebagai salah satu UKM yang berlokasi di Bandung, Arafa Tea memiliki beberapa keterbatasan dalam hal sumber daya untuk melaksanakan program komunikasi pemasaran. Keterbatasan ini meliputi sumber daya manusia, biaya dan teknologi yang diadaptasi oleh Arafa Tea. Berikut adalah batasan yang dimiliki oleh Arafa Tea:

1. Biaya: Arafa Tea menetapkan biaya pemasaran sebesar 5\% dari total pendapatan, yaitu berkisar Rp.800.000,-

2. Sumber Daya Manusia: Arafa Tea memiliki 8 pegawai dimana 5 diantaranya ditempatkan di bagian produksi, 2 di bagian pengemasan dan 1 orang di bagian pemasaran .

3. Arafa Tea menggunakan media berbasis internet berupa aplikasi instant messaging untuk berkomunikasi dengan pelanggan dan pegawai.

\section{Benchmarking}

Benchmarking dilakukan untuk mencari kesenjangan yang terdapat dalam praktek komunikasi pemasaran yang dilakukan oleh Arafa Tea. Hasil benchmarking akan berfungsi sebagai dasar untuk menentukan target pengembangan komunikasi pemasaran dan strategi pemasaran yang tepat untuk Arafa Tea. Tabel 3 dan Tabel 4 menunjukkan benchmarking yang dilakukan.

TABEL III

BENCHMARKING ANTARA ARAFA TEA DENGAN TAMA COKELAT

\begin{tabular}{|c|c|c|}
\hline & \multicolumn{2}{|r|}{ UKM } \\
\hline & Arafa Tea & Tama Cokelat \\
\hline Produk & GTC & Chocodot \\
\hline Target Pasar & $\begin{array}{l}\text { Anak muda kelas } \\
\text { menengah }\end{array}$ & $\begin{array}{l}\text { Anak muda kelas } \\
\text { menengah }\end{array}$ \\
\hline $\begin{array}{l}\text { Rata-rata } \\
\text { pendapatan } \\
\text { perbulan }\end{array}$ & 24 Juta Rupiah & 1 Milyar Rupiah \\
\hline Area pemasaran & $\begin{array}{l}\text { Lembang, } \\
\text { Ciburial, }\end{array}$ & $\begin{array}{l}\text { Bandung, Jogjakarta, } \\
\text { Jakarta dan kota besar di } \\
\text { Jawa }\end{array}$ \\
\hline $\begin{array}{l}\text { Media } \\
\text { komunikasi }\end{array}$ & $\begin{array}{l}\text { Brosur, banner } \\
\text { dan pameran }\end{array}$ & Kemasan dan pameran \\
\hline $\begin{array}{l}\text { Konten pada } \\
\text { media } \\
\text { komunikasi }\end{array}$ & $\begin{array}{l}\text { Status, Informasi } \\
\text { produk }\end{array}$ & Informasi produk \\
\hline $\begin{array}{l}\text { Program } \\
\text { komunikasi } \\
\text { pemasaran saat } \\
\text { ini }\end{array}$ & $\begin{array}{l}\text { Kemasan } \\
\text { sederhana, public } \\
\text { relations, promosi } \\
\text { penjualan, word of } \\
\text { mouth dan } \\
\text { pameran. }\end{array}$ & $\begin{array}{l}\text { Kemasan yang dirancang } \\
\text { divisi desain, public } \\
\text { relations, promosi } \\
\text { penjualan, pameran, } \\
\text { penyebaran agen dan } \\
\text { Reseller, dan internet } \\
\text { marketing yang ditangani } \\
\text { oleh divisi khusus. }\end{array}$ \\
\hline
\end{tabular}

TABEL IV

\begin{tabular}{|c|c|c|}
\hline & \multicolumn{2}{|r|}{ UKM } \\
\hline & Arafa Tea & Maicih \\
\hline Produk & GTC & Keripik Singkong \\
\hline $\begin{array}{l}\text { Target } \\
\text { Pasar }\end{array}$ & $\begin{array}{l}\text { Anak muda, } \\
\text { kelas menengah }\end{array}$ & $\begin{array}{l}\text { Anak muda, kelas } \\
\text { menengah }\end{array}$ \\
\hline $\begin{array}{l}\text { Rata-rata } \\
\text { Omset } \\
\text { setiap bulan }\end{array}$ & $\begin{array}{l}\text { Dua puluh empat } \\
\text { juta Rupiah }\end{array}$ & $\begin{array}{l}\text { Satu milyar tujuh ratus } \\
\text { juta Rupiah }\end{array}$ \\
\hline $\begin{array}{l}\text { Area } \\
\text { Pemasaran }\end{array}$ & $\begin{array}{l}\text { Lembang, } \\
\text { Ciburial, }\end{array}$ & Indonesia \\
\hline $\begin{array}{l}\text { Media } \\
\text { Komunikasi }\end{array}$ & $\begin{array}{l}\text { Brosur, banner } \\
\text { dan pameran }\end{array}$ & $\begin{array}{l}\text { Interactive marketing } \\
\text { dan kemasan }\end{array}$ \\
\hline $\begin{array}{l}\text { Konten } \\
\text { pada Media } \\
\text { Komunikasi }\end{array}$ & $\begin{array}{l}\text { Status, Informasi } \\
\text { produk }\end{array}$ & Foto, Informasi Produk. \\
\hline $\begin{array}{l}\text { Praktik } \\
\text { Komunikasi } \\
\text { Pemasaran }\end{array}$ & $\begin{array}{l}\text { Kemasan } \\
\text { sederhana, } \\
\text { public relations, } \\
\text { promosi } \\
\text { penjualan, word } \\
\text { of mouth dan } \\
\text { pameran. }\end{array}$ & $\begin{array}{l}\text { Sosial media / } \\
\text { interactive marketing, } \\
\text { komunikasi yang } \\
\text { dilakukan oleh Reseller } \\
\text { melalui program jendral } \\
\text { gentayangan, kemasan } \\
\text { yang dirancang khusus. }\end{array}$ \\
\hline
\end{tabular}


Berdasarkan hasi benchmarking dapat disimpulkan bahwa sasaran pengembangan komunikasi pemasaran yang lebih baik jika dilakukan untuk Maicih sedangkan untuk pengembangan strategi pemasaran dilakukan terhadap Chocodot.

\section{Target Pengembangan}

Analisis kesenjangan yang telah dilakukan pada tahap benchmarking terhadap Chocodot dan Maicih menghasilkan kesenjangan dan rekomendasi dalam strategi pemasaran dan komunikasi pemasaran yang digunakan oleh Arafa Tea. TABEL V

\begin{tabular}{|c|c|c|c|}
\hline \multicolumn{4}{|c|}{ TARGET PENGEMBANGAN STRATEGI PEMASARAN } \\
\hline $\begin{array}{l}\text { Benchmark } \\
\text { parameter }\end{array}$ & $\begin{array}{l}\text { Performance } \\
\text { Indicator }\end{array}$ & GTC & $\begin{array}{l}\text { Target } \\
\text { Pengembagan }\end{array}$ \\
\hline Pendapatan & Pendapatan & 25 Juta Rupiah & - \\
\hline \multirow[t]{2}{*}{$\begin{array}{l}\text { Area } \\
\text { Pemasaran }\end{array}$} & $\begin{array}{l}\text { Area } \\
\text { Pemasaran }\end{array}$ & $\begin{array}{l}\text { Ciburial, } \\
\text { Lembang }\end{array}$ & $\begin{array}{l}\text { Ciburial, } \\
\text { Lembang, } \\
\text { Bandung }\end{array}$ \\
\hline & Distribusi & $\begin{array}{l}\text { Outlet, } \\
\text { Pameran }\end{array}$ & $\begin{array}{l}\text { Reseller, Outlet, } \\
\text { Pameran }\end{array}$ \\
\hline \multirow[t]{2}{*}{$\begin{array}{l}\text { Target } \\
\text { Pasar }\end{array}$} & Segmen & $\begin{array}{l}\text { Youth middle } \\
\text { class }\end{array}$ & - \\
\hline & $\begin{array}{l}\text { Existing } \\
\text { consumer }\end{array}$ & $\begin{array}{l}\text { Turis dan } \\
\text { pengunjung } \\
\text { pameran }\end{array}$ & $\begin{array}{l}\text { Youth middle } \\
\text { class }\end{array}$ \\
\hline
\end{tabular}

TABEL VI

TARGET PENGEMBANGAN PROGRAM KOMUNIKASI PEMASARAN

\begin{tabular}{|c|c|c|c|}
\hline $\begin{array}{l}\text { Benchmark } \\
\text { parameter }\end{array}$ & $\begin{array}{l}\text { Performance } \\
\text { Indicator }\end{array}$ & GTC & $\begin{array}{l}\text { Target } \\
\text { Pengembangan }\end{array}$ \\
\hline \multirow[t]{2}{*}{$\begin{array}{l}\text { Communic } \\
\text { ation media }\end{array}$} & $\begin{array}{l}\text { Media yang } \\
\text { digunakan }\end{array}$ & $\begin{array}{l}\text { Outlet, } \\
\text { Pameran }\end{array}$ & $\begin{array}{l}\text { Interactive } \\
\text { Marketing, } \\
\text { Reseller, } \\
\text { Packaging }\end{array}$ \\
\hline & $\begin{array}{l}\text { Fans } \\
\text { Follower }\end{array}$ & 340 & - \\
\hline \multirow[t]{2}{*}{ Konten } & $\begin{array}{l}\text { Frekuensi } \\
\text { post }\end{array}$ & - & 1 post perhari \\
\hline & Tipe konten & 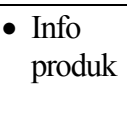 & $\begin{array}{ll}- & \text { Info } \\
& \text { produk } \\
\text { - } & \text { Foto }\end{array}$ \\
\hline
\end{tabular}

\section{HASIL DAN PEMBAHASAN}

Berdasarkan analisis yang telah dilakukan dapat diketahui bahwa untuk meningkatkan penjualan, Arafa Tea perlu memperluas pasar dengan meningkatkan efektifitas program komunikasi pemasaran. Program komunikasi pemasaran yang dimaksudkan adalah pengembangan kemasan produk untuk menarget segmen yang dituju, mengoptimalkan penggunaan media interaktif sebagai komunikasi pemasaran dan pelaksanaan program reseller.

\section{A. Kemasan}

Kemasan usulan GTC Arafa Tea didesain oleh pihak yang telah berpengalaman. Unsur dan elemen kemasan baru dapat dilihat pada Tabel 5.

TABEL VII

KONSEP KEMASAN USULAN GTC ARAFA TEA

\begin{tabular}{|l|l|l|}
\hline No & $\begin{array}{l}\text { Elemen } \\
\text { kemasan }\end{array}$ & \multicolumn{1}{c|}{ Keterangan } \\
\hline 1 & Desain & $\begin{array}{l}\text { Kombinasi warna yang digunakan adalah } \\
\text { hijau dan putih mencerminkan tentang } \\
\text { produk Arafa Tea yang mengusung tema } \\
\text { kesehatan. Grafis yang digunakan juga } \\
\text { disesuaikan dengan selera target pasar. }\end{array}$ \\
\hline 2 & Informasi & $\begin{array}{l}\text { Informasi yang terdapat pada kemasan } \\
\text { produk adalah nama produk, merek atau } \\
\text { merek dagang, logo, informasi tentang } \\
\text { bahan tambahan makanan, deskripsi } \\
\text { bahan yang digunakan (komposisi) }\end{array}$ \\
\hline 3 & Material & Art paper dengan laminasi \\
\hline
\end{tabular}

B. Media Interaktif

Usulan media komunikasi pemasaran seperti penggunaan media interaktif yang berupa media berbasis internet karena merupakan media yang dapat digunakan secara gratis, hal ini dirasa tepat mengingat keterbatasan biaya yang dimiliki oleh Arafa Tea. Hal ini juga didukung oleh Indonesia yang berada di posisi keenam dalam jumlah pengguna internet di dunia. Pengguna internet di Indonesia mencapai 33\% dari total populasi yaitu sebanyak 88.100.000 pengguna. Pengguna internet di Indonesia adalah pengguna dengan umur rata-rata 18 tahun untuk 65 tahun.

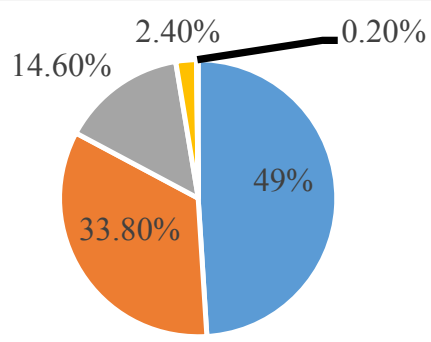

- 18-25 Year old = 26-35 Year old = 36-45 Year old

-46-55 Year old $\bullet 56-65$ Year old

Gambar 3 Distribusi umur pengguna internet di Indonesia [9]

Berdasarkan Gambar 3 dapat dilihat bahwa pengguna internet didominasi oleh pengguna dengan rentang umur 18 sampai 35 tahun. Berdasarkan hal tersebut penggunaan media komunikasi berbasis internet dianggap tepat karena 
target pasar Arafa Tea adalah anak muda dengan rentang umur 18 sampai 30 tahun.

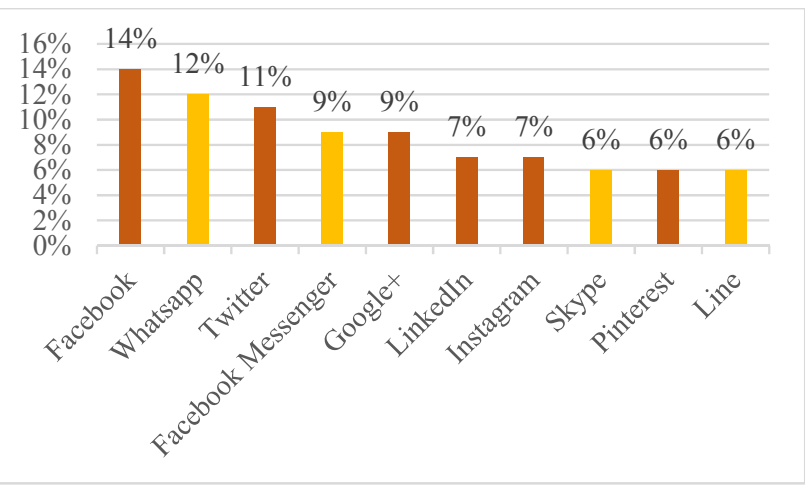

Gambar 4 Persentase pengguna media sosial [10]

Gambar 4 menunjukkan jumlah pengguna aktif media komunikasi berbasis internet. Jumlah pengguna aktif merepresentasikan potensi penyebaran informasi, promosi dan penjualan [11]. Facebook menempati urutan pertama dalam hal jumlah tertinggi, oleh karena itu Facebook dipilih sebagai media komunikasi yang direkomendasikan.

\section{Reseller}

Untuk memasarkan produk GTC ke kota Bandung Arafa Tea perlu menambahkan saluran distribusi untuk mendistribusikan produk GTC kepada calon konsumen. Saluran distribusi yang diusulkan juga harus mempertimbangkan kemampuan Arafa Tea segi biaya. Oleh karena itu program reseller adalah salah satu saluran distribusi yang dirasa tepat karena selain dapat menjadi media komunikasi Arafa Tea, reseller juga hampir tidak memerlukan biaya yang besar.

\section{Langkah Implementasi}

Rencana implementasi program komunikasi pemasaran terpadu dilakukan setelah menentukan usulan program komunikasi seperti Facebook, reseller dan kemasan. Rencana implementasi akan dilakukan sesuai dengan urutan prioritas yang dapat dilihat pada Tabel 6 .

TABEL VIII

PRIORITAS PROGRAM KOMUNIKASI PEMASARAN

\begin{tabular}{|c|l|c|l|}
\hline Usulan & Kemampuan & Prioritas & \multicolumn{1}{|c|}{ Keterangan } \\
\hline Kemasan & Biaya yang & 1 & Dapat \\
& cukup, & & memberikan \\
& memiliki & & dampak langsung \\
& relasi & & dan Arafa Tea \\
& dengan & & memiliki biaya \\
& pihak & & untuk menerapkan \\
& percetakan. & & kemasan usulan. \\
\hline
\end{tabular}

\begin{tabular}{|l|l|c|l|}
\hline Facebook & $\begin{array}{l}\text { Memiliki } \\
\text { akses } \\
\text { internet., } \\
\text { memiliki } \\
\text { laptop. }\end{array}$ & 2 & $\begin{array}{l}\text { Facebook } \\
\text { diterapkan setelah } \\
\text { Arafa Tea } \\
\text { menggunakan } \\
\text { kemasan baru } \\
\text { agar promosi } \\
\text { hanya dilakukan } \\
\text { terhadap satu } \\
\text { desain kemasan. }\end{array}$ \\
\hline Reseller & - & 3 & $\begin{array}{l}\text { Dapat } \\
\text { memperluas area } \\
\text { distribusi }\end{array}$ \\
\hline
\end{tabular}

\section{KESIMPULAN}

Berdasarkan tujuan dari penelitian ini dapat disimpulkan bahwa Arafa Tea sebagai UKM yang memiliki produk berpotensi yang belum menggunakan komunikasi pemasaran terintegrasi secara efektif dan efisien. Hal ini berbeda dengan pesaing yang telah berhasil memasarkan produk dengan jenis yang sama dengan menggunakan strategi komunikasi pemasaran yang efektif.

Hasil benchmarking dilakukan pada Chocodot adalah untuk menemukan kesenjangan dalam strategi pemasaran menghasilkan kesimpulan bahwa Arafa Tea perlu untuk memperluas pasarnya ke kota Bandung.

Berdasarkan hasil benchmarking yang dilakukan pada Maicih ditemukan kesenjangan pada komunikasi pemasaran yang telah dilakukan oleh Arafa Tea. Dari kesenjangan tersebut dapat dirumuskan bahwa Arafa Tea perlu meningkatkan kemasan, penggunaan media sosial dan program reseller untuk meningkatkan penjualan.

Rekomendasi yang diberikan kepada Arafa Tea adalah perumusan program komunikasi pemasaran terpadu yang disesuaikan dengan kemampuan dan sumber daya Arafa Tea agar dapat diimplementasi secara efektif dan efisien.

\section{DAFTAR PUSTAKA}

[1] Kementerian Koperasi dan Usaha Kecil dan Menengah Republik Indonesia (2012). Dari Statistik UKM 2012. http://www.depkop.go.id/index.php?option=com_phoc adownload\&view $=$ category\&id=124: statistik-ukm2012\&Itemid $=93$, diakses pada tanggal 21 November 2014

[2] Kotler, P., \& Keller, K. L. (2009). Marketing Management. London: Pearson Education .Inc.

[3] Daniels, S. (1996). Benchmarking. Work Study, 45(3).

[4] Kodali, G. A. (2008). Benchmarking the bencmarking models. Benchmarking: An International Journal, 15(3). 
[5] Elmuti, D., \& Kathawala, Y. (1997). An overview of benchmarking: a tool for continuing improvement and competitive advantage. Benchmarking for quality management and technology, 4.

[6] Belch, G. E., \& Belch, M. A. (2003). Advertising and Promotion: An Integrated Marketing Communiations Perspective (Vol. 6). Mc. Graw-Hill

[7] Kotler,P., \& Keller, K. L. (2009). Marketing Management. London: Pearson Education .Inc.

[8] Andy Neely Mike Gregory Ken Platts, (1995),"Performance measurement system design", International Journal of Operations \& Production Management, Vol. 15 Iss 4 pp. $80-116$.

[9] CNN Indonesia, (2015). Demografi Pengguna Internet Indonesia. Dari CNN Indonesia. http://www.cnnindonesia.com/teknologi/20150327134 253-188-42341/demografi-pengguna-internetindonesia/, diakses pada tanggal 20 Mei 2015.
[10]TechInAsia, (2015). Laporan Pengguna Website Mobile Media Sosial Indonesia. Dari TechInAsia. http://id.techinasia.com/laporan-pengguna-websitemobile-media-sosial-indonesia/, diakses pada tanggal 20 Mei 2015

[11]Forbes, (2015). The Top 10 Benefits of Social Media Marketing. Dari

Forbes.com. http://www.forbes.com/sites/jaysondemers/2014/08/11 /the-top-10-benefits-of-social-media-marketing/, diakses pada tanggal 3 Juli 2015 